\title{
вмJ Global Health Significance of informal (on-the-job) learning and leadership development in health systems: lessons from a district finance team in South Africa
}

\author{
S Choonara, ${ }^{1} \mathrm{~J}$ Goudge, ${ }^{1} \mathrm{~N}$ Nxumalo, ${ }^{1} \mathrm{~J}$ Eyles ${ }^{1,2}$
}

To cite: Choonara S,

Goudge J, Nxumalo N, et al. Significance of informal (onthe-job) learning and leadership development in health systems: lessons from a district finance team in South Africa. BMJ Global Health 2017;2:e000138. doi:10.1136/bmjgh-2016000138

Received 26 July 2016 Revised 29 November 2016 Accepted 1 December 2016

CrossMark

${ }^{1}$ Centre for Health Policy, MRC Health Policy Research Group, School of Public Health, University of the Witwatersrand

Johannesburg, South Africa

${ }^{2}$ School of Geography and Earth Sciences, McMaster University, Hamilton, Ontario, Canada

Correspondence to

S Choonara;

shakira288@gmail.com

\section{ABSTRACT}

Background: The district health system (DHS) has a critical role to play in the delivery of primary healthcare (PHC). Effective district management, particularly leadership is considered to be crucial element of the DHS. Internationally, the debate around developing leadership competencies such as motivation or empowerment of staff, managing relationships, being solution driven as well as fostering teamwork are argued to be possible through approaches such as formal and informal training. Despite growing multidisciplinary evidence in fields such as engineering, computer sciences and health sciences there remains little empirical evidence of these approaches, especially the informal approach. Findings are based on a broader doctoral thesis which explored district financial management; although the core focus of this paper draws attention to the significance of informal learning and its practical value in developing leadership competencies.

Methods: A qualitative case study was conducted in one district in the Gauteng province, South Africa. Purposive and snowballing techniques yielded a sample of 18 participants, primarily based at a district level. Primary data collected through in-depth interviews and observations (participant and nonparticipant) were analysed using thematic analysis.

Findings: Results indicate the sorts of complexities, particularly financial management challenges which staff face and draws attention to the use of two informal learning strategies-learning from others (how to communicate, delegate) and fostering team-based learning. Such strategies played a role in developing a cadre of leaders at a district level who displayed essential competencies such as motivating staff, and problem solving.

Conclusions: It is crucial for health systems, especially those in financially constrained settings to find cost-effective ways to develop leadership competencies such as being solution driven or motivating and empowering staff. This study illustrates that it is possible to develop such competencies through creating and nurturing a learning environment (on-the-job training) which could be incorporated into everyday practice.

\section{Key questions}

What is already known about this topic?

- Existing literature outlines two possible approaches for leadership development. The first approach involves formal training through university courses or workshops, while the second approach involves workplace-based learning/ informal on-the-job learning.

What are the new findings?

- Leadership is critical in building resilient and effectively functioning health systems. There has been much focus on developing leadership competencies through the formal approach; however, there remains little empirical evidence of informal learning and its role in developing leadership competencies.

- The article points out two informal learning strategies-learning from others (communication and delegation) as well as fostering team-based learning which nurtured leadership in the finance team and in some parts of the broader district.

\section{Recommendations for policy}

- This article offers first-hand accounts, experiences and practical strategies which can be incorporated into everyday settings.

- While the advantages of formal learning have been documented in the literature, some weaknesses reported include difficulty applying theory/knowledge to work settings or formal learning being expensive. Informal learning addresses challenges associated with formal learning, it is also associated with team-based learning/fostering teamwork.

- Given the financial constraints that many low and middle-income settings face, these findings offer practical strategies which are useful and draw attention to cost-effective ways of developing leadership competencies.

\section{INTRODUCTION}

The process of decentralisation through the transfer of power and authority from higher levels to lower levels of the health system has 
been implemented in a number of developing countries with a view to improve efficiency, innovation and allow for adaptation of service delivery to the local level. ${ }^{1}$ Post-1994, the South African (SA) government committed to decentralisation through the establishment of the district health system (DHS). ${ }^{2}$ The DHS has a critical role to play in the delivery of primary healthcare (PHC) and basic services in many developing countries. ${ }^{3}$ WHO guidelines/recommendations have emphasised the need to strengthen and have in place a well-functioning DHS. ${ }^{4}$ Effective district management is critical in achieving health reforms, however, the DHS in many developing countries are staffed by individuals who have not been adequately trained to be leaders in their settings and SA is no exception to this. ${ }^{25}$

Some studies consider leadership and management separately, although it has been argued that management and leadership overlap in practice and that both are crucial in strengthening the DHS. ${ }^{6}{ }^{7}$ Management involves coordinating technical processes such as planning and budgeting, whereas leadership refers to individuals who create a vision, inspire, motivate and enable staff to achieve results in complex conditions. ${ }^{7}$ While the article was cognisant of the importance of management competencies in DHS settings, it's primary focus was to draw attention towards the value of informal learning in developing leadership competencies such as motivating and inspiring staff.

This paper draws on a larger doctoral study, which focused on financial management at a district level. Financial management consists of four distinct processes which occur in a cyclical manner. Processes include, financial planning, resource allocation and budgeting, oversight and evaluation. ${ }^{8}$ While the doctoral thesis was geared to provide an in-depth account of financial management and its technical processes, for example, planning or budgeting, it attempted to understand this core district function in terms of its realities and practices. Its core focus was to examine organisational elements of financial management such as communication, relationships and mentorship. This paper is primarily based on empirical evidence which emerged from the findings and outlines informal learning strategies employed in the finance team as well as the broader district and its role in nurturing leadership, in particular developing necessary leadership competencies.

A recent review focused on developing leadership and management capacities in low and middle-income countries (LMICs) found that formal training (through university courses and workshops) remains a common approach to develop leadership and management in these settings. ${ }^{7}$ The review found that formal training while useful, primarily focused on development of technical competencies such as programme management and financial management. While formal training is advantageous and it is probably those who have formal training who are responsible for informal learning, a noted disadvantage is that managers even in settings such as the UK found it difficult to transfer knowledge from formal education to on-the-job challenges. ${ }^{7}$ In other countries such as SA, going on formal training meant returning to an even higher workload. ${ }^{9}$

The workplace is seen as a learning environment based on life experiences or realities and is said to enhance or supplement formal education and nurture personal development in the workplace. ${ }^{10}$ Workplacebased (informal) learning is another approach which supports development of leadership competencies which could enable responses to changing circumstances in the workplace and brings about the importance of learning or developing through practice. ${ }^{5} 11$ Practical ways to ensure that learning happens effectively can be developed through training in the workplace and particularly through team-based learning and mentorship which is considered to be an effective means of modelling behaviour. ${ }^{5}$ Another benefit from the informal learning approach, is fostering teamwork especially in settings where learning can be a shared responsibility, that is, learning together, which is more advantageous in comparison to formal learning. ${ }^{5}{ }^{11}$ Quite a few disciplines consider the workplace to be a learning environment which allows for constant learning from life experiences or realities and offers benefits such as complementing formal education and nurturing personal development in the workplace..$^{10}$

Situated learning and organisational learning theories also emphasise the importance of contextual learning in the workplace which encourages creative problem solving despite constraints and learning from each other including from more experienced staff or managers. ${ }^{12}$ There has been increased focus on experiential learning in engineering, computer sciences and health sciences disciplines, which have examined curricula development. ${ }^{10}$ Despite noted advantages of informal learning and addressing the shortfalls of formal learning, for example, difficulty applying what is learnt or allowing for broader shared learning, there remains little empirical evidence of these approaches in actual healthcare settings. The focal point of the paper moves beyond financial management to illustrate the significance of informal learning in developing leadership competencies in the finance team and the broader DHS.

\section{METHODS \\ Study site}

SA is divided into nine provinces, Gauteng is considered to be the most populous province and the economic hub of the country. ${ }^{13}$ The SA health system is comprised of three tiers, namely; national, provincial and local (district and subdistrict level). The study reports on findings from one district (Isikhala) in the Gauteng province of SA. The Isikhala district was used to replace the existing district name to ensure that ethical considerations were met-for example, anonymity and confidentiality of participants. The district and province were selected for the 
doctoral study as researchers were in close proximity to the district, thereby reducing fieldwork costs and allowing for more timely data collection. The SA government is presently pursuing its National Health Insurance (NHI) Scheme-a Universal Health Coverage (UHC) Strategy through which pilot sites (districts) have been selected and are being researched, these sites are undergoing substantial change, for example, additional resources for new projects. ${ }^{14}$ The Isikhala district has not been selected as an NHI pilot site, comparatively it is considered to be relatively under-researched and is comprised of some semirural parts which also tend to be under-researched in the SA context, thus allowing insight into leadership in these areas.

\section{Study design}

The primary aim of qualitative research is to provide rich understandings of a specific context including social realities or perspectives of the given topic ( $R$ Greenstein, B Roberts, A Sitas. Research methods training manual. 2003 (unpublished)).The core focus of the doctoral thesis was to document and provide an in-depth analysis of district financial management. A case study design was appropriate and useful in providing a thorough understanding and analysis of the specific (district) context. ${ }^{15}$ While this paper will draw out some financial management challenges; it is centred on emergent themes linked to informal learning and offers insight into the practicalities of leadership development in a district setting.

\section{Sampling and study population}

Literature indicates that purposive sampling is usually considered to be suitable for case study designs. ${ }^{15}$ The purposive sampling method was used to identify key informants involved in financial management processes at a district level-the Isikhala district consists of nine staff members within the finance unit who were all included in the study. Snowballing sampling was used to identify the remaining participants, in the broader district including the subdistrict level, who were linked to or carried out some finance related tasks (human resources (HR), information technology (IT), health information systems (HIS) and procurement), this included further nine participants. One additional participant (identified) refused to be interviewed and was thus excluded. A total of 18 participants made up the study population. Figure 1 depicts the structure of the district, deputy directors (DDs), assistant directors (ADs) and the entire finance unit/section as well as the level, type and range of participants who were selected for the study.

\section{Data collection}

Primary data were collected as part of the doctoral thesis, by the main author of this article with close to

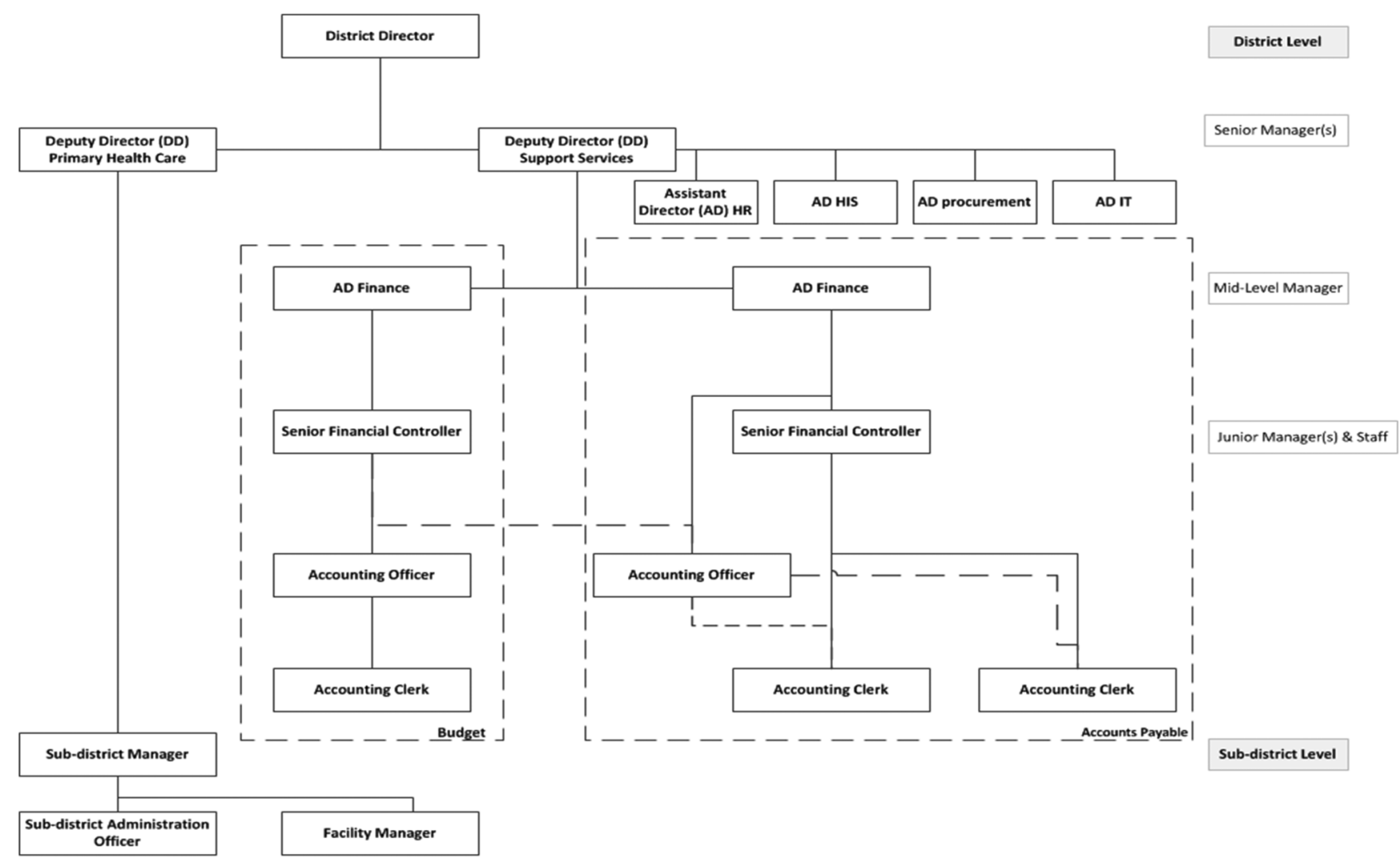

Figure 1 Participants included in the study. HIS, health information systems; IT, information technology. 
5 years of qualitative research experience. Data collection methods included in-depth interviews and observations which spanned across 1 year (between March 2015 and February 2016).

In-depth interviews were carried out with each of the participants illustrated in figure 1 and used to prompt and understand individual's roles (including management roles), background, specific financial management expertise and processes, cognisant of organisational factors such as relationships, communication and motivation. Follow-up interviews were carried out with some participants for clarification of information or further detail. Each interview lasted for $\sim 45 \mathrm{~min}$ to an hour. Two types of observational techniques were employed in the study, namely non-participant and participant observations. Initially, non-participant observation was used. Non-participant observation involved minimal participation of the researcher in actual processes and the researcher maintained a distanced stance from these processes. ${ }^{16}$ Through liaison with the district finance team and ethics/research officer, non-participant observations included job shadowing individuals in finance, linked functions in procurement and meetings. Non-participant observation aided in fostering relationships and building trust between the researcher and participants and addressing observer bias-participants altering behaviour during observations. ${ }^{17}$ Non-participant observation assisted with broadly understanding financial management, and supplementing information collected during in-depth interviews as well as identifying further processes/meetings to be observed. Participant observation started when the researcher was requested to actively participate in everyday processes, for example, budgeting or to provide assistance on some financial tasks, it aided with providing further validity to research findings from the specific setting and also resulted in informal/ on-the-job learning for the researcher around principles and implementation of financial management at a district level. All three techniques provided a rich understanding and validity of findings were confirmed through triangulation of data methods.

\section{Conceptual framework and theoretical lens}

Below is a conceptual framework which outlines some of the leadership competencies in the paper-a few shown to be developed through informal learning practices. Structuration theory highlights the importance of agency in leadership development.

The theory asserts that agents and structures are not independent but dependent phenomena, whereby the one creates or confines and recreates the other. ${ }^{18}$ Agency refers to the microlevel (individual human actors), as opposed to structure which refers to large-scale social structures (rules and resources). ${ }^{19}$ Structuration theory is based on the premise that structure will not exist without the actions of individual agents, thus there needs to be a balance created between the two. ${ }^{18}$ There has been much contestation over the importance of structure over agency and vice versa. The literature asserts that constant stress and constraints, often linked to structures such as limited resources or infrastructure at a district level require leaders who are able to express and display agency. ${ }^{9} 20$ For example, some financial management constraints noted in districts in Uganda, Tanzania and Ghana include bureaucratic processes to access and use funds, the late disbursement of funds, and national planning guidelines not linked to district-level planning needs. ${ }^{3}{ }^{21}{ }^{22}$ In SA, inadequate delegation of authority and defective budgeting processes plague district financial management. ${ }^{2}$ There is a need to develop a cadre of leaders who will be able to work with and confront these sorts of challenges often linked to structural factors (limited resources or difficult rules/processes to access resources) and who manage through innovation and action that is, leaders who will express agency despite systemic constraints.

Such leaders require competencies listed in table 1which is the basis of the conceptual framework of the study and is an adaptation of the SA Department of Public Service and Administration (DPSA) as well as previous literature by Gilson and Daire (2011) who highlight these competencies for dealing with constraints in health settings. The table adapted from Gilson and Daire (2011), was used as an overarching framework as it deals specifically with necessary competencies in the SA health sector. This paper has shown the importance of these competencies among leaders across different levels of the health system, and considers how some of these competencies were developed through the informal learning approach.

\section{Data analysis and ethical considerations}

Data collected were transcribed and thoroughly analysed, at first by the doctoral researcher and then together with oversight and input with the coauthors (supervisors). There are six steps to thematic analysis outlined in the literature. ${ }^{24}$ Steps include the coding of material, identifying themes, constructing thematic networks, describing and exploring the networks, summarising of all information and interpreting patterns within the themes. Data revealed themes specific to financial management; however, emergent themes included informal learning strategies which were the focus of this paper. Initial analysis of in-depth interviews revealed specific informal learning strategies used to motivate staff, for example, delegation and how staff viewed such strategies as well as how the district dealt with challenging situations. Elements of informal learning in relation to leadership emerged as a recurrent theme; the literature was then searched for a relevant leadership competency framework in the SA health context. Data were reanalysed by the authors (separately and together) who interrogated and discussed discrepancies in coding informal learning strategies and any evidence of leadership competencies listed in table 1 as well as in 
Table 1 DHS leadership competencies ${ }^{23}$

\begin{tabular}{|c|c|}
\hline Competency & Description \\
\hline $\begin{array}{l}\text { 1. People management and } \\
\text { empowerment }\end{array}$ & $\begin{array}{l}\text { Must be able to manage and encourage people, optimise their outputs and effectively } \\
\text { manage relationships in order to achieve organisational goals }\end{array}$ \\
\hline 2. Problem solving and analysis & $\begin{array}{l}\text { Must be able to systematically identify, analyse and resolve existing and anticipated } \\
\text { problems in order to reach optimum solutions }\end{array}$ \\
\hline $\begin{array}{l}\text { 3. Programme and project } \\
\text { management }\end{array}$ & $\begin{array}{l}\text { Must be able to plan, manage, monitor and evaluate specific activities in order to deliver the } \\
\text { desired outputs }\end{array}$ \\
\hline 4. Knowledge management & $\begin{array}{l}\text { Must be able to promote the generation and sharing of new knowledge and learning in } \\
\text { order to enhance the collective knowledge of an organisation }\end{array}$ \\
\hline $\begin{array}{l}\text { 5. Strategic capability and } \\
\text { leadership }\end{array}$ & $\begin{array}{l}\text { Must be able to provide a vision, set the direction for the organisation and inspire others in } \\
\text { order to deliver on the organisational mandate }\end{array}$ \\
\hline 6. Communication & $\begin{array}{l}\text { Must be able to exchange information and ideas in a clear and concise manner appropriate } \\
\text { for the audience in order to explain, persuade, convince and influence others to achieve the } \\
\text { desired outcome }\end{array}$ \\
\hline 7. Financial management & $\begin{array}{l}\text { Must be able to compile and manage budgets, control cash flow, institute risk management } \\
\text { and administer tender procurement processes in accordance with generally recognised } \\
\text { financial practices in order to ensure achievement of strategic organisational objectives }\end{array}$ \\
\hline 8. Change management & $\begin{array}{l}\text { Must be able to initiate and support organisational transformation and change in order to } \\
\text { implement new initiatives successfully and deliver on service delivery commitments }\end{array}$ \\
\hline 9. Service delivery innovation & $\begin{array}{l}\text { Must be able to explore and implement new ways of delivering services that contribute to } \\
\text { the improvement of organisational processes to achieve organisational goals }\end{array}$ \\
\hline $\begin{array}{l}\text { 10. Client orientation and } \\
\text { customer focus }\end{array}$ & $\begin{array}{l}\text { Must be willing and able to deliver services effectively and efficiently in order to put the } \\
\text { spirit of customer service into practice }\end{array}$ \\
\hline 11. Honesty and integrity & $\begin{array}{l}\text { Must be able to display and build the highest standards of ethical and moral conduct in } \\
\text { order to promote confidence and trust in the public service }\end{array}$ \\
\hline
\end{tabular}

relation to structuration theory which provided the overall theoretical framework of the doctoral study also relevant to this article. Specific themes and subthemes were then developed inductively based on emergent themes and the literature. Records of all decisionmaking processes were documented through minute taking and constant reflection by the doctoral researcher.

Ethical permission to conduct the study was granted by the Gauteng Province, University of the Witwatersrand, Human Research Ethics Committee (medical) and by the relevant district-level authority. Ethical considerations included informed consent forms administered to each participant prior to interviews and observations, anonymity and confidentiality of all participants was guaranteed, with pseudonyms being created for the district. This ensured that there was no possible identification of study participants whose names or identities were not used in any data analysis or dissemination material.

\section{RESULTS}

This paper draws attention to the value of informal learning in developing leadership competencies in a district finance team, with some insights into the broader district. In order to gauge the complexities that participants face in the health system, a brief overview if given over some structural constraints and daily challenges in terms of financial management which is also closely linked to other support functions such as procurement and IT. Leadership involves being able to confront such complexities, and going against all odds. To facilitate this, it was critical that leadership competencies discussed in table 1 were developed. Two informal learning strategies, namely, the importance of learning from others (delegation, communication) and team-based learning are discussed.

\section{DHS constraints}

Under decentralisation, sufficient power and autonomy is meant to be transferred to the lower levels of the health system, particularly the DHS. A number of participants highlighted difficulties associated with certain support-side functions and processes (financial management which is also closely linked to procurement and IT), particularly described as being linked to limited power or authority delegated to the district level. The main challenges discussed in relation to financial management included bureaucratic processes, accessing the available resources (budget), delayed procurement and difficulties around IT. One of the reasons for continued centralisation was that for a certain period of time, the Provincial Treasury Department placed the Provincial Department of Health (DoH) under administration due to overexpenditure-strict control measures over resources were put in place, all requests and budgets had to be approved by Treasury, instead of just the DoH. 
Centralisation of support-side functions such as creating purchase orders, approval to use funds, IT equipment plans and infrastructure plans were also centralised functions.

Participants noted that the listed structural constraints (centralisation and inadequate delegation/authority) affected district support-side functions. A key challenge raised by participants was difficulty in accessing the budget-available financial resources, associated with bureaucratic processes/provincial approval. For example, one participant mentioned how he had drawn up infrastructure plans for storage space of medications over a decade ago. However, the budget remains controlled by another provincial department, which made it difficult to have plans approved. Inaccessibility to available financial resources was echoed by number of other participants in HR, IT and even health programmes.

Delayed approval of procurement orders by central levels also impacted service delivery;

Dry dispensary, basic items such as needles and bandages are often out-of-stock at many facilities. We were told that the purchase of these items now requires provincial approval. I submitted all the documents and have been following-up, however, these requests have still has not been approved. The clinics do not have these necessities. This results in unnecessary referrals to higher levels, example hospitals, when these services could have easily been carried out at a lower level, that is, the clinic level (mid-level manager 1).

Regarding IT, staff in finance explained daily tasks were severely impacted by slow network connectivity and a lack of IT equipment-'severely impeding our ability to carry out tasks and meet deadlines'. It was noted that there was no internet connectivity and a minimal amount of IT equipment within the district and at the subdistrict level and this also hampered communication via emails within and beyond the district. These are just some of the challenges which emerged from the doctoral study which offers more in-depth insight and analysis of financial management; however, some of these findings have been outlined to provide some context to the structural constraints which exists and its impact on district-level functioning. Employing some of the informal learning strategies, discussed below was one way of developing leadership competencies which enabled finance staff to deal with such constraints in a district setting.

\section{Informal learning in the workplace}

Findings revealed that informal learning in the broader district was fostered through learning from superiors or through team-based strategies;

\section{Strategy 1: learning from other leaders-the art} of delegation and communication

A few of the participants offered accounts of how SA's racially segregated past (apartheid) provided a strict and deadline-driven environment with little room for innovation in the health sector. Non-Caucasians employed in the health sector faced discrimination in terms of job placements and lower wages. Yet, despite SA's difficult circumstances, the district manager recounted how she was shaped by the rigid apartheid system (which was considered to be militant and punitive) and how she learnt on-the-job through interaction with her supervisors.

I'm one of the few black nurses who worked in this area under apartheid. Apartheid was good and bad, it was a struggle but it also taught us to work hard and know what you're aiming for. It also taught me that deadlines are important, even today I make sure that people don't go beyond their deadlines... When I was appointed in a senior position, I was struggling to do everything and it's my manager that taught me you cannot do everything. I learnt from that day that delegation is not a bad thing and it provides a challenge to those below and it's encouraging, it shows them that you believe they can do it (district manager).

In turn, staff learnt the art of delegation from the district manager and incorporated it into their own units/ divisions - for example, in the PHC and procurement unit, but particularly of interest in the finance unit. The delegation of tasks was seen as a means of learning, personal development and motivation;

Another positive thing about our manager is that she allows you to be a manager; she provides challenges and I learnt a lot (senior manager 1 ).

My manager's doors are always open; they are like work fathers, always trying to teach you. They give you opportunities and challenges and even take you to some meetings to learn and see how things happen (Lower level manager 2).

The district manager also placed emphasis on establishing good relationships with staff through communication-either through meetings or through one-on-one discussions to provide feedback. Managers across the district described how they learnt such communication skills from the district manager:

I learnt from the district manager, she's one of the managers' who has continuously given me feedback and now I have implemented this-I also give feedback to staff below me (senior manager 1 ).

Learning from other managers, filtered down to even lower level staff, junior participants in finance acknowledged learning how to manage others and to prioritise from their supervisors;

When I started off in finance, he showed me how to prioritise tasks... Being a manager is difficult at times, but my manager taught me to keep a diary and record everything, both the positive to acknowledge good work and 
the negative so that you have proof when it is time for performance management. I learnt all of this from him, he is a very good supervisor, and he is a leader (lower level manager 1 ).

\section{Strategy 2: team-based learning-exploring the financial management unit}

Finance managers in particular revealed how they introduced informal learning through the broader district environment and went on to fostering teamwork in their unit as well as stressed the importance of empowering others:

We as managers are judged by the team we have created. It is important that we ensure that we develop them; we encourage them to learn new tasks and functions and even encourage them to go the extra mile (mid-level manager 2).

Often managers encouraged staff to work together on tasks-this allowed staff to learn different tasks, support and advise each other (peer-learning). In addition, each staff member was trained on every finance-related task, this provided knowledge of other team member functions, allowed staff to stand-in if others resigned or went on leave. The entire finance unit with the exception of the managers were placed together in one openplanned office space. The close proximity of staff members enabled them to interact, support and advise each other which further enacted informal learning. This approach allowed for individual and team learning, personal development and teamwork:

The finance manager encouraged us to learn everything (all tasks) in finance, so that you understand the entire department, you are not limited and it will be easy to grow (lower level manager 1).

We work together as a team quite often; we really do have teamwork. For instance, there are many clinics and budget capturing is quite intensive. The finance managers will request that we work together on this task, we put our own work aside, and assist each other until the task is complete, then we go back to our own tasks (lower level manager 1).

The learning environment together with staff being given the responsibility and space to implement activities (through delegation) allowed staff to appreciate challenges and perceive them as learning curves. Informal practices was one mechanism which contributed to developing a cadre of leaders who learnt from their superiors and developed competencies such as delegating as a means of empowering and motivating staff, communicate/manage others, prioritising and fostering teamwork. Further results indicate that this cadre went on to display competency 2 in table 1 (problem solving and analysis), coping strategies, solutions and innovations and were able to express agency when addressing the DHS constraints listed earlier.

\section{Solution-driven and motivated leadership}

This section outlines how the informal learning environment, coupled with motivation and teamwork were linked to the specific competency (problem solving and analysis) drawing on examples from the broader district and a few examples specific to the finance team. There was an instance where a clinic did not have adequate storage space for medications and there was no budget for building additional space. The issue was escalated to the district level, where one of the managers said, 'there is no place for excuses, we can work around this'. Petty cash was used to purchase the material and one of the medical practitioners who knew how to build or repair items was requested to assist. He placed shelves throughout one room of the clinic to maximise space for the storage of some medications. Other cases involved providing a few short-term solutions or coping strategies. Procurement staff who were also motivated by the district manager's delegation strategies (described above) and being within this solution-driven environment explained that even though it was difficult to keep to prescribed levels of stock as they had minimal storage space; they ordered less more often or even allowed for borrowing of equipment and stock between facilities to ensure that service delivery remains unaffected.

Problems with IT connectivity were described as 'frustrating' by most staff; some said that it was even difficult to carry out their daily tasks as they are unable to access necessary systems due to slow connectivity. Observations through job shadowing of some finance staff, confirmed how staff would make appointments at the provincial level to make use of the computer facilities to complete tasks. The finance managers explained their problem-based coping strategies, that is, how they worked around these IT constraints;

We don't limit staff, sometimes the systems are down. We arrange and allow for them to work at another hospital or clinic in the area where the systems are functional. Some of them even go to use the systems at province (mid-level manager 2).

In the broader district as well as in the finance unit, managers (senior and junior) reported difficult relationships with staff below/demotivated staff. Participants displayed competency 1 and 5 from table 1 in particular (people management and empowerment as well as communication);

As a manager it is important to be strong minded and also accommodative, you need to take different personalities, strengths and weaknesses into cognisance. As a manager there's no way that you cannot be autocratic at times. One needs to strike a balance between democracy and autocracy. There are times that you have to push people, some individuals are like wheel barrows once you leave them in a certain place, you will still find them there. So you have no choice but to nudge and push 
them to meet their deadlines and encourage a high quality of work (district manager).

Being a manager is like being a parent, you can be angry at your child today but at the end of the day he or she is still your child and you will need to manage that child whether you like it or not. It is important to sit down and discuss the issue and provide feedback. There are other times when we as managers are also wrong and we apologise. We have an open door policy, to come and discuss work and personal issues. There will always be issues you know though we try to handle them as if we are parents instead of managers (mid-level manager 2).

One way that this cadre of leaders motivated staff was by finding innovative strategies, for example, in the finance unit, managers related that simple strategies such as acknowledging good work, went a long way in motivating staff. Another initiative which played a role in staff motivation was the district's annual awards ceremony. There was an awards committee and a template which managers used to track progress, and included indicators such as hard work, punctuality and innovation of any individuals or teams at the subdistrict and district level. Individuals and teams were nominated and an awards committee organised and provides oversight around the process. The overall winner from the subdistrict also had the opportunity to be selected for the district award. At a district level, members based within this positive learning environment and across various units including, finance, IT, procurement and on the service delivery side shared their views on the awards ceremony;

I won the award last year. I only received a certificate, but it means a lot to be acknowledged. I believe it doesn't always have to be a monetary reward, but just somebody acknowledging that what you are doing is good (senior manager 2).

I think it is very good. It encourages a person to perform. It is very important in an organisation to acknowledge good performance; if there are no rewards then we might not be as innovative or creative (lower level staff).

Despite the learning and solution-driven environment created as well as displays of agency, health systems are complex and continue to be inherently affected by structural influences. For example, individuals in the district try to find solutions (express their agency) or keep following up on documents and processes. However, the lack of authority and external influences were found to impede agency. A few of the managers specifically raised concerns around how decision-making authority was transferred in theory and not in practice. Some district participants gave details of how they carried out necessary disciplinary processes in line with guidelines, legislations and rules and with the assistance of district HR. There were some cases where individuals were dismissed and the district's decision was overturned by the unions and province. In essence as one participant stated:

The challenge when you're based at a district is that you can be innovative but the reality is that you always have to get permission from the province or national (senior manager 2).

Although similar levels of agency were not as eminent at a subdistrict level in comparison to the district levelinformal learning strategies and teamwork were described as being difficult to extend. At a subdistrict level, a number of staff stated that due to many constraints it was more difficult to exercise agency. Some participants explained that their constraints also included IT and procurement challenges, however, in comparison to the district these challenges were further compounded by the lack of sufficient administrative capacity at a subdistrict level. Participants reported that they did try to find solutions such as communicating telephonically or via the mobile application (WhatsApp) or using personal resources (own laptop or collecting money to purchase own cleaning materials), however, systemic constraints made it difficult to be innovative/ solution driven;

We raised these issues with our managers, informally and through meetings, we tried to find solutions but it is difficult, nothing ever improves. We put through our submissions on time to the administrative officer, who takes the documents to the district office, but he doesn't have a computer or email address, it's difficult to follow-up, though we do follow-up, nothing happens, there is nonagency in government and that constrains us. When the time comes, we do not even have cleaning materials for our facilities (subdistrict staff 1).

Nonetheless, even with such constrains, participants at the district level, particularly in the finance team displayed how they continuously tried to push boundaries and find solutions. This is largely attributed to staff reporting being motivated through informal practices such as delegation (new opportunities) and continuous learning;

It is a joy working here, you are not limited, you are allowed to spread your wings and grow, it is solely dependent on you whether you do so (mid-level manager 2 ).

\section{DISCUSSION}

WHO recognises leadership to be a critical component of a well-functioning health system. ${ }^{25}$ The onset of democracy in SA in 1994 saw an exodus of skilled workers from the health workforce and since the country has been grappling with a loss of institutional memory (experience and knowledge of processes and organisation). There have been some levels of leadership displayed and there are competent leaders in the system, although addressing the gap remains a challenge. ${ }^{26}$ 
Such challenges are also imminent in other postconflict settings especially in sub-Saharan Africa. LMICs face resource constraints which render formal training to develop leadership competencies costly; there is thus a need to focus on more cost-effective approaches. Participants who undergo formal training have cited difficulties in applying knowledge gained to everyday settings and challenges. Such shortfalls may be addressed and complemented through approaches such as on-the-job training which allows for context-specific learning. Minimal literature focusses on the value of informal learning in developing such leadership. Results from this study reveal that learning from superiors is one way of shaping leaders who learn to delegate and communicate (table 1 competency knowledge management, people management/empowerment and communication). In particular, insights are offered into informal strategies which could be incorporated into workplace settings in an LMIC context such as SA.

Previous literature sees on-the-job learning as having only medium potential in acquiring skills in developing and implementing action plans, understanding techniques and acquiring knowledge. ${ }^{7}$ However, this study offers evidence of the importance of on-the-job learning in developing leadership competencies-it further enabled leaders in the finance unit to foster team-based learning, teamwork and agency when dealing with complex situations. Easily implementable informal learning strategies (learning from others, and delegation/ communication) by the district manager filtered down to staff directly below her, particularly in the finance unit and in other divisions in the district as well. The type of leadership nurtured in this district is captured in the quote below:

The essential task of leadership is creating opportunities, releasing potential, removing obstacles, encouraging growth and providing guidance-Adapted. ${ }^{27}$

A prior study in SA highlights the high workload of district managers as one of the factors impeding their ability to effectively manage the district. ${ }^{28}$ The district manager in this study provided insight into the twofold benefit of delegation. First it reduced her workload and also provided other managers the opportunity and space to learn, develop and be innovative. Managers below her as well as others were guided, learnt from her and modelled this behaviour when dealing with difficult situations, and were action oriented despite constraints; for example, being able to provide adequate infrastructure to clinics despite having a minimal budget.

As mentioned 'knowledge management' is one of the critical components of the framework (table 1) - being able to promote the generation and sharing of knowledge and learning in order to enhance collective knowledge of the organisation. ${ }^{7}$ An example of this is the finance managers who inculcated collective knowledge in their unit by allowing each staff member to be trained on every section of finance and encouraged working together on certain financial tasks.

Finally, evidence contributes to the ongoing debate on structure and agency, which requires a critical balance between the two phenomena. While structural challenges linked to centralisation, particularly limited authority have been discussed, it's important to note that the broader centralisation-decentralisation debate, which has associated difficulties in terms of measurement and the need for centralisation to achieve economies of scale and provide oversight. ${ }^{29}{ }^{30}$ Nonetheless, this paper argues that there needs to be a balance between the structure and agency phenomenon-as it was noted that even though agency was encouraged, there were instances where it was constrained and participants felt that the centralisation of certain functions continued to impede there agency. However, despite the listed constraints, through developing such leadership competencies, numerous participants still displayed agency or tried to (go against the odds) when addressing such challenges.

\section{Limitations and further research}

This doctoral study attempted to understand financial management and study participants were primarily limited to those involved in district finance; these findings are also limited to one context. However, the paper draws attention to informal learning (emergent themes from study data), which has been relatively underresearched. Findings are thus not necessarily transferrable to other settings, where coupled with different types of personalities and leadership may yield different results. However, the aim of qualitative research is not to generalise but instead to provide rich, in-depth accounts of a specific context which reflect social realities such as personal experiences and relationships and important in drawing practical lessons and insight into everyday settings and daily practice. While the impact of on-the-job learning is likely to be difficult to measure in other contexts, the study offered novel insight and much needed empirical evidence in the field-practical insight and examples around the significance of workplace-based learning as a strategy to developing critical leadership competencies within a finance unit and the broader DHS. Furthermore, it points to strategies which may easily be incorporated into practice, including delegation and fostering teamwork through shared learning.

Further research may be needed to identify if there are other informal strategies which may be used and consider linkages between formal and informal learning, as well as considering further qualitative and quantitative measures of these approaches and their impacts. Components of investigation could focus on an individual's background, characteristics which may also be linked to the development of leadership competencies. Moreover, further studies could delve deeper into differences/a comparison of impact and development of 
competencies at different levels of the health system, for example, provincial, district and subdistrict levels.

The observation technique of research has not been viewed or thoroughly explored as an on-the-job learning/development of technical skills. Through nonparticipant and participant observation, the researcher was taught by district staff and gained insight into financial management practices, systems and principles. This also points to observational research being a strategy for researchers to learn more and gain a deeper understanding of health systems. Informal learning despite its difficulties to measure and issues around generalisability has shown to be valuable in this district and is aligned to arguments made in prior management literature which states that learning technical skills on site and in the workplace is also argued to inspire staff members enthusiasm, creativity and commitment, moreover it encourages shared learning. ${ }^{26}$ Further studies focussing on informal learning are thus essential to developing the field and knowledge base of informal learning in healthcare organisations.

\section{CONCLUSION}

Effectively functioning districts are dependent on leaders who display agency despite systemic constraints. Building on strategies to develop such leaders and sustaining these gains will be critical to strengthening health systems. Financial constraints and challenges of implementing formal once-off courses continue to hinder leadership development in LMICs. Health systems need to find ways of developing leaders through cost-effective mechanisms that are able to respond to complex challenges. One possible approach this study draws on is the informal learning approach which could be incorporated into everyday settings and practice. Two strategies, particularly learning from other managers allowed for competencies such as delegation which motivated staff and allowed for further learning (knowledge management) in the broader district, but specifically in the finance team. Delegation, for example, served as a strategy for informal learning which could easily be integrated into practices in other settings. Second, allowing for team-based learning in the finance unit nurtured teamwork. These two strategies contributed to developing such competencies as well as creating leaders who were solution driven, that is, such as staff in the finance unit who despite mentioned constraints worked around budget accessibility issues and IT challenges.

\section{Handling editor Stephanie Topp.}

Twitter Follow Shakira Choonara @ChoonaraShakira

Acknowledgements SC, JG and NN are members of the Consortium for Resilient and Responsive Health Systems (RESYST). This document is an output from a project funded by the UK Aid from the UK Department for International Development (DFID) for the benefit of developing countries. The doctoral study in particular is nested within RESYST and is supported by the National Research Foundation (NRF) of SA, through the Freestanding Doctoral
Scholarship and the SA Research Chairs Initiative (SARChl) under JE. Financial assistance of the NRF is here acknowledged.

Contributors SC carried out data collection, analysis and was responsible for write-up and drafts of the manuscript. JG and JE, NN served as supervisors on the doctoral thesis including this manuscript-providing oversight, input and discussions during various stages of this research.

Funding National Research Foundation South Africa Research Chairs Initiative (SARChl) and Freestanding Doctoral Scholarship, Resilient and Responsive Health System Consortium, University of the Witwatersrand, School of Public Health, Seed Funding Grant.

Disclaimer The views expressed and information contained in it is not necessarily those of or endorsed by DFID, which can accept no responsibility for such views or information or for any reliance placed on them. Opinions expressed and conclusions arrived at others of and not necessarily attributed to the NRF and other funders.

\section{Competing interests None declared.}

Ethics approval University of the Witwatersrand Human Research Ethics Committee (medical), Gauteng Provincial Department of Health and Isikhala Health District.

Provenance and peer review Not commissioned; externally peer reviewed.

Data sharing statement This manuscript is part of a larger doctoral thesis, focussing on financial management (well beyond this manuscript), the majority of the data has been added to the doctoral thesis which will be published by the university on graduation. Associated manuscripts based on the thesis have been submitted to journals (such as this submission) However, there may be small components which did not fit/not relevant to the write-ups, only the student (author) and supervisors (coauthors) have access to the data (electronic/soft copies) which according to ethical agreements if not used will be discarded over the next 4 years.

Open Access This is an Open Access article distributed in accordance with the Creative Commons Attribution Non Commercial (CC BY-NC 4.0) license, which permits others to distribute, remix, adapt, build upon this work noncommercially, and license their derivative works on different terms, provided the original work is properly cited and the use is non-commercial. See: http:// creativecommons.org/licenses/by-nc/4.0/

\section{REFERENCES}

1. Bossert TJ, Beauvais JC. Decentralization of health systems in Ghana, Zambia, Uganda and the Philippines: a comparative analysis of decision space. Health Policy Plann 2002;17:14-31.

2. Wolvaardt $G$, Johnson $S$, Cameron $D$, et al. Challenges and constraints at district management level. South Afr Health Rev 2013;14:81-92.

3. Asante AD, Zwi AB, Ho MT. Getting by on credit: how district health managers in Ghana cope with the untimely release of funds. BMC Health Serv Res 2006;6:105.

4. WHO. The challenge of implementation: district health systems for primary health care. Geneva, 1988 (cited 2016 07/07). http://www. ais.up.ac.za/med/pcm870/challenge.PDF

5. Doherty J, Gilson L. Workplace-based learning for health system leaders: practical strategies for training institutions and governments. Resilient and Responsive Health System Consortium. 2015 (cited 2016 02/26). http://resyst.Ishtm.ac.uk/sites/resyst.Ishtm.ac.uk/files/ docs/reseources/Leadership\%20workshop\%20report_0.pdf

6. Conn CP, Jenkins P, Touray SO. Strengthening health management: experience of district teams in The Gambia. Health Policy Plann 1996;11:64-71.

7. Daire J, Gilson L, Cleary S. Developing leadership and management competencies in low and middle income country health systems: a review of the literature-Working Paper 4. Resilient and Responsive Health System Consortium. 2014 (cited 2016 02/26). http://resyst. Ishtm.ac.uk/sites/resyst.Ishtm.ac.uk/files/docs/reseources/WP4_ Developing\%20leadership\%20and\%20management\% 20competencies.pdf

8. Engelbrecht B, Jooste $\mathrm{H}$, Muller $\mathrm{G}$, et al. Financial management: an overview and field guide for district management teams. 2002 (cited 2016 08/28). http://www.hst.org.za/uploads/files/finmanage.pdf

9. Schaay N, Heywood A, Lehmann U. Health service management training. In: Antoinette N, ed. South African Health Review. Health 
Systems Trust; 1998. http://www.hst.org.za/publications/southafrican-health-review-1998

10. Kolb DA. Experential learning: experience as a source of learning and development. 2nd edn. USA: Pearson Education Inc, 2015.

11. Raelin JA. A model of work-based learning. Organ Sci 1997;8:563-78.

12. Dochy FG, Segers D, Van Den Bossche MP. Theories of learning for the workplace: building blocks for training and professional development programs. Routledge psychology in education series. New York, USA: Routledge, 2011.

13. Gauteng department of health and social development. Annual performance plan: 2011/2012-2013-14. 2011 (cited 2016 03/25). http://www.health.gpg.gov.za/dohDocuments/Annual\% 20Performance\%20Plans/Annual\%20Performance\%20Plan\% 202011-12\%20201314.pdf

14. Department of Health South Africa. White paper National Health Insurance for South Africa: towards universal health coverage. 2015 (cited 2016 08/20). https://www.health-e.org.za/wp-content/uploads/ 2015/12/National-Health-Insurance-for-South-Africa-White-Paper.pdf

15. Creswell JW, Creswell JW. Qualitative inquiry and research design, choosing among five approaches. Los Angeles: SAGE publications, 2013.

16. Robson C. Real world research: a resource for social scientists and practitioner-researchers. Oxford, UK: Blackwell Publishers, 2002.

17. Monahan T, Fisher JA. Benefits of "observer effects": lessons from the field. Qual Res 2010;10:357-76.

18. Giddens A. The constitution of society: outline of the theory of struturation. Los Angeles: University of California Press, Berkley, 1984.

19. Mcgraw-Hill. Chapter 15: sociological theory. agency structure integration (cited 29 Feb 2016). highered.mcgrawhill.com/sites/ 0072817186/student view0/chpater15/chapter summary.html

20. Elloker S, Olcker P, Gilson L, et al. Crises, routines and innovations: the complexities and possibilities of sub-district management: leadership and governance. In: Padarath A, English R, eds. South
African Health Review. Health Systems Trust; 2012. http://www.hst. org.za/publications/south-african-health-review-2012/13

21. Nnaji GA, Oguoma C, Nnaji LI, et al. The challenges of budgeting in a newly introduced district health system: a case study. Glob Public Health 2010;5:87-101.

22. Kivumbi GW, Nangendo F, Ndyabahika BR. Financial management systems under decentralization and their effect on malaria control in Uganda. Int J Health Plann Manag 2004;19(Suppl 1): 117-S131.

23. Gilson L, Daire J. Leadership and governance within the South African health system. In: Padarath A, English R, eds. South African Health Review. Health Systems Trust; 2011. http://www.hst.org.za/ publications/south-african-health-review-2011

24. Attride-Stirling J. Thematic networks: an analytical tool for qualitative research. Qual Res 2001;1:385-405.

25. Seims LRK, Alegre JC, Murei L, et al. Strengthening management and leadership practices to increase health-service delivery in Kenya: an evidence-based approach. Hum Resour Health 2012;10:25-25.

26. Butler A. Black economic empowerment. (cited 2016 04/25). http:// www.yale.edu/macmillan/apartheid/apartheid_part1/butler.pdf

27. Management Sciences for Health. Managers who lead: a handbook for improving health services. Cambridge, Massachusetts: Management Sciences for Health, 2008.

28. Masilela T, Molefakgotla P, Visser R. Voices of district managers. In: Antoinette N, ed. South African Health Review. Health Systems Trust; 2001. http://www.hst.org.za/publications/south-african-healthreview-2001

29. Bossert T. Analysing the decentralization of health systems in developing countries: decision space, innovation and performance. Soc Sci Med 1998;47:1513-27.

30. Hendricks SB, Seekoe E, Bossert T, et al. Decentralisation in South Africa: options for district health authorities in South Africa. South Afr Health Rev 2014:4:5972. 